\title{
Studies on structure and properties of CNSL novolac resins prepared with succinic acid catalyst
}

\author{
K SATHIYALEKSHMI \\ Department of Chemistry, Sree Devi Kumari Women's College, Kuzhithurai, Kanyakumari \\ District 629 163, India
}

MS received 29 August 1991; revised 17 July 1992

\begin{abstract}
Cashew nut shell liquid (CNSL) was used to prepare a glass fabric laminate. Two fast curing model resins were prepared using cardanol and formaldehyde in the presence of succinic acid catalyst. The resins possess ortho-ortho and ortho-para linkages. The curing kinetics of the resins showed that the resin prepared with mole ratio 0.8 possesses good curing characteristics. The IR spectra of cured resin showed responses for high ortho linkage. A CNSL high ortho novolac resin was prepared with mole ratio 0-8. The glass fabric laminates prepared with CNSL resin showed good mechanical properties and dimensional stability. It is suggested that the candidate laminate can be used as secondary load bearing structures or panels.
\end{abstract}

Keywords. Novolac resins; succinic acid; cashew nut shell liquid; curing; glass fabric laminate.

\section{Introduction}

Phenolic resins are a class of synthetic materials that have found increasing applications in recent years. Due to the decline in supply and price fluctuations in petroleum raw materials, the use of natural products from renewable sources is gaining importance. Cashew nut shell liquid (CNSL) obtained from cashew-tree nuts (Anacardium occidentale) is used to develop a variety of industrial products. The production of cashew nut, which has grown steadily in the last two decades, should yield $25 \%$ of the by-product technical CNSL though processing losses result in smaller yield (Dhler 1979). CNSL is obtained during isolation of the kernels by roasting the raw nuts or by the hot oil process. The principal components of natural CNSL are anacardic acid, cardol, 2-methylcardol and anacardol (Tyman 1979). On heating, anacardic acid is decarboxylated to cardanol. The thermally treated CNSL contains a mixture of cardol, cardanol and a small amount of self-polymerized CNSL. Cardanol is a npentadecadienyl phenol, the aliphatic side chain usually consists of mixtures of one, two and three double bonds in a linear chain with saturated side chain $5.4 \%$, monolefin $48.5 \%$, diolefin $16.8 \%$ and triolefin $29.33 \%$ (Murthy et al 1968 ).

Substituted phenols used for preparation of substituted phenolic resin (Redfarn 1942; Freeman and Traylar 1961) differ in their reactivity with formaldehyde. Therefore, it is of interest to study the formylation of cardanol and curing of methylolated cardanol in the presence of acid catalyst. It has been found that the use of certain metal salts e.g. zinc, magnesium or calcium acetate etc. under an intermediate alkaline pH 4-7 and 15-30\% molar excess of phenol over formaldehyde results in the formation of novolac that have a disproportionately high concentration of ortho-ortho repeat units (Bender et al 1949). The unique properties displayed by high ortho novolacs are cure speed and rheological properties. However, the effect of metta-substituted 
long chain in cardanol on curing characteristics of high ortho CNSL based novolac resin is one aspect which needs further studies. Jayabalan and Rajadurai (1985) prepared high ortho cardanol-based novolac resin using $m$-cresol, a trifunctional accelerator (crosslinker) and alkali catalyst ( $\mathrm{pH} 9$ ). Studies on the formylation of cardanol leading to high ortho novolac and curing of such novolac in the absence of accelerator are scarce.

Oxalic acid has been used as an acid catalyst to produce novolac phenolic resin with a pH range of 0.5 to 1.5 . It is known that acids in which there are two carbonyl groups separated by a chain of more than 5 carbon atoms, have different properties. The acid strength of the dicarboxylic acid as measured by the first dissociation constant $K_{1}$ decreases with increasing number of bonds between the two carbonyl groups. $K_{1}$ values at $25^{\circ} \mathrm{C}$ being $6.6 \times 10^{-5}$ for succinic acid, $4.7 \times 10^{-5}$ for glutaric acid and $3.7 \times 10^{-5}$ for adipic acid. With the low acid strength which falls in the $\mathrm{pH}$ range $4-7$, the higher aliphatic dicarboxylic acid can influence formylation and orientation of cardanol. Information on the catalytic effect of aliphatic dicarboxylic acid on the formylation of cardanol and curing, as high ortho novolac resin, is scarce. Attempts have therefore been made to study the use of an aliphatic dicarboxylic acid such as succinic acid as a catalyst. This paper deals with studies on the formylation of cardanol, curing characteristics of formylated product and preparation of CNSL resin and laminate.

\section{Experimental}

\subsection{Materials}

CNSL was procured from local sources. Cardanol was obtained from $\mathrm{M} / \mathrm{s}$ Card-chem Industries, Hyderabad. Formaldehyde ( $40 \%$ solution) $(\mathrm{BDH})$ was used for formylation. Succinic acid (E-Merck) was used as a catalyst and methanol (BDH) was used to dissolve the catalyst. Hexamine was used for curing the resin.

\subsection{Analyses of cardanol and CNSL}

Cardanol and CNSL were subjected to extensive analyses such as determination of saponification value, iodine value, viscosity test, specific gravity, volatile matter at $200^{\circ} \mathrm{C}$, moisture content and insoluble matter in toluene following standard procedures (ISI Standard 840-1964).

\subsection{Synthesis of cardanol-formaldehyde model novolac resin}

Novolac resins with two different mole ratios i.e. 1:0.6 and 1:0.8 of cardanol to formaldehyde were prepared using succinic acid as the catalyst. Catalyst $(1 \%)$ based on cardanol was dissolved in $2 \mathrm{ml}$ methanol under warm conditions. Cardanol was weighed into a three-necked flask fitted with a Leibig's condenser, ground joint thermometer and mercury seal stirrer. Formaldehyde $(40 \%)$ solution was added to cardanol through a dropping funnel along with the catalyst. The $\mathrm{pH}$ of the reaction mixture was noted using a $\mathrm{pH}$ meter. The reaction mixture was heated to $120 \pm 5^{\circ} \mathrm{C}$ 
under constant stirring for $3 \mathrm{~h}$. The reaction mixture $(1 \mathrm{ml})$ was withdrawn for determining formaldehyde to check the completion of methylolation reaction (Urbanski et al 1977). The final $\mathrm{pH}$ of the mixture was noted. The reaction product was cooled and dried under vacuum at $60^{\circ} \mathrm{C}$ overnight before purification by column chromatography. A resin solution prepared with $n$-hexane was charged to the silica gel column. Chromatographic purification was adopted mainly to remove unreacted components, impurities, etc. from the methylolated cardanol. Purification was effected using the elutant mixture of ethylacetate/benzene (60:40). The purified resin was analyzed by ultraviolet spectral analysis (as $0.05 \%$-hexane solution), IR spectral analyses (as resin smear on sodium chloride window) and proton NMR spectral analyses (as carbon tetrachloride solution).

\subsection{Curing kinetics and IR spectral analysis of cured (B-stage) resin}

The oven-dried model cardanol-formaldehyde resin was treated with $18 \%$ hexamethylene tetramine and blended well using mortar and pestle. Approximately $5 \mathrm{mg}$ of blended resin was taken to study the curing kinetics of the resin by differential thermal analysis. A thermal analyser 990 Dupont was used with reference thermocouple loaded with micro glass beads. The glass beads were wetted with silicone oil to nullify the high thermal conductivity of the resin. Initially DTA cell was heated isothermally at $25^{\circ} \mathrm{C}$ for $15 \mathrm{~min}$. The cell was then heated up to a maximum temperature of $200^{\circ} \mathrm{C}$ at $10^{\circ} \mathrm{C} / \mathrm{min}$ under nitrogen atmosphere. The curing kinetics curve appeared as a function of change in enthalpy with temperature. In a separate experiment the hexamine-blended resin was cured at $157^{\circ} \mathrm{C}$ under nitrogen atmosphere for $1 \mathrm{~h}$ in a baking oven. The cured product (B-stage) was then taken for IR spectral analysis.

\subsection{Synthesis of CNSL-formaldehyde resin}

CNSL novolac resin was prepared using CNSL and formaldehyde in the ratio of $1 \cdot 0: 0 \cdot 8$ with succinic acid as catalyst ( $1 \%$ based on CNSL). CNSL and formaldehyde were allowed to react at $90-95^{\circ} \mathrm{C}$ for $2 \mathrm{~h}$. The temperature was then raised to $120-130^{\circ} \mathrm{C}$ and kept for $1 \mathrm{~h}$. The reaction product was cooled, dried under vacuum at $60^{\circ} \mathrm{C}$ overnight and used for fabrication of glass fabric laminate.

\subsection{Fabrication of glass fabric laminate}

CNSL novolac resin was dissolved in benzene/methanol $(1: 1)$ mixture to get a syrup and mixed with $18 \%$ hexamine and stirred well to get a homogeneous mixture. The glass fabric woven cloth (E glass, satin weave, 15 mil, 8 hardness) was cleaned well with methanol and dried in an oven at $100^{\circ} \mathrm{C}$ for $30 \mathrm{~min}$. It was then uniformly coated with resin syrup using a brush. The resin-coated glass fabric cloth (prepreg) was then air-dried overnight. The prepreg was trimmed to get a rectangular sheet $(12 \times 8 \mathrm{~cm})$. Four sheets were stacked in a hand press and compressed manually. The hand press was kept in an air oven set at $200^{\circ} \mathrm{C}$ for $1 \mathrm{~h}$. The hand press was then taken out, cooled to room temperature and the pressure released. The cured sheets were cut into rectangular coupons for tensile tests and water absorption. 


\subsection{Tensile tests of glass fabric laminate}

The laminates were tested for tensile properties (ASTM standard D3039-76) using an Instron Universal testing machine. The gauge length of the specimen was $127 \mathrm{~mm}$ and the area of cross-section $0.2 \mathrm{~cm}^{2}$. The cross-head and chart speeds were both $100 \mathrm{~mm} / \mathrm{min}$. Six specimens were tested for each sample and the average value computed.

\subsection{Tests for water absorption}

The laminates were cut into square specimens (1 square inch), cleaned with distilled water and dried. After weighing, the samples were immersed in distilled water. The water absorption was determined by measuring the sample weight increase periodically.

\section{Results and discussion}

\subsection{Analysis of cardanol and CNSL}

CNSL is usually obtained in India by a crude thermal process and the technical CNSL contains large amounts of ash and other charred products of cashew. Analysis of cardanol and CNSL is therefore desirable for phenolic resin preparation. The analytical data of cardanol and CNSL are presented in table 1 and the values compared with that of standard technical CNSL oil. The lesser viscosity of the

Table 1. Properties of cardanol and cashew nut shell liquid.

\begin{tabular}{|c|c|c|c|}
\hline Properties & Cardanol & CNSL & $\begin{array}{c}\text { Standard* } \\
\text { technical } \\
\text { CNSL }\end{array}$ \\
\hline Colour & Dark brown & Dark brown & Dark brown \\
\hline Smell & $\begin{array}{l}\text { Mild phenolic } \\
\text { odour }\end{array}$ & $\begin{array}{l}\text { Smoky and mild } \\
\text { phenolic odour }\end{array}$ & $\begin{array}{l}\text { Smoky and mild } \\
\text { phenolic odour }\end{array}$ \\
\hline $\begin{array}{l}\text { Specific gravity } \\
(\mathrm{g} / \mathrm{cc}) \text { at } 30^{\circ} \mathrm{C}\end{array}$ & 0.873 & 0.962 & 0.960 \\
\hline $\begin{array}{l}\text { Viscosity (CPS) } \\
\text { at } 30^{\circ} \mathrm{C}\end{array}$ & $38 \cdot 2$ & 228 & 550 \\
\hline $\begin{array}{l}\text { Saponification } \\
\text { value }\end{array}$ & $.22 \cdot 4$ & 121 & - \\
\hline Iodine value & $274 \cdot 8$ & 278 & 250 \\
\hline $\begin{array}{r}\text { Volatile matter } \\
\text { at } 200^{\circ} \mathrm{C}(\%)\end{array}$ & $4 \cdot 0$ & $4 \cdot 2$ & $2 \cdot 0$ \\
\hline $\begin{array}{c}\text { Moisture content } \\
\text { at } 100^{\circ} \mathrm{C}(\%)\end{array}$ & $2 \cdot 6$ & $2 \cdot 1$ & 10 \\
\hline $\begin{array}{l}\text { Insoluble matter } \\
\text { in toluene }(\%)\end{array}$ & 0.6 & $1 \cdot 3$ & $1 \cdot 0$ \\
\hline
\end{tabular}

* ISI standard 840-1964 
Table 2. Formulation of model cardanol-formaldehyde resin.

\begin{tabular}{lcccccccc}
\hline \multirow{3}{*}{$\begin{array}{l}\text { Mole ratio of } \\
\text { formaldehyde } \\
\text { to cardanol }\end{array}$} & $\begin{array}{c}\text { Cardanol } \\
(\mathrm{g})\end{array}$ & $\begin{array}{c}\text { Formalde- } \\
\text { hyde }(\mathrm{g})\end{array}$ & $\begin{array}{c}\text { Succinic } \\
\text { acid }(\mathrm{g})\end{array}$ & & $\begin{array}{c}\text { Cardanol } \\
(\mathrm{g})\end{array}$ & $\begin{array}{c}\text { Formalde- } \\
\text { hyde }(\mathrm{g})\end{array}$ & $\begin{array}{c}\text { Succinic } \\
\text { acid (g) }\end{array}$ \\
\hline 0.6 & 87.6 & 13.5 & 0.876 & & - & - & - \\
0.8 & - & - & - & 75.5 & 15.0 & 0.755 \\
\hline
\end{tabular}

cardanol indicates lesser ash content and non-self-polymerization. The iodine value represents the degree of unsaturation. Cardanol exists in three different olefinic forms with varied degrees of unsaturation in the long aliphatic side chain. The higher iodine value of cardanol and CNSL indicates the higher degree of unsaturation in comparison to the standard CNSL oil.

\subsection{Synthesis of cardanol-formaldehyde model resin}

The methylolation of cardanol was carried out initially according to the formulation shown in table 2 . Succinic acid was used as a catalyst. The acid strength of this dicarboxylic acid was lower than that of the oxalic acid. The $\mathrm{pH}$ of the reaction mixtures for the model resins $\mathrm{K}-\mathrm{I}$ and $\mathrm{K}-\mathrm{II}$ was 4 during initiation of the reaction indicating that the succinic acid imparts intermediate alkaline $\mathrm{pH}$ under the present formulations of reaction mixtures as per the norms of $\mathrm{pH}$ of phenolic resins suggested by Finn and Murty (1950). The methylolation reactions were carried out with 0.6 and 0.8 mole ratio of formaldehyde to cardanol. Therefore under this experimental condition the complete formylation is expected to yield resin with high ortho-ortho linkage as observed by Fraser et al (1957) for phenolic novolac resins.

The completion of the methylolation reaction was checked by periodic withdrawal of reaction mixture to analyse formaldehyde using hydroxylamine hydrochloride (Urbanski et al 1977). The final $\mathrm{pH}$ of the reaction mixture was 2 . The decrease of $\mathrm{pH}$ in the methylolated cardanol is ascribed to the monohydroxyl substituted cardanol. Sperling (1954) found that methylolated phenol favours hydrogen bonding with $o$-methylol and hydroxyl groups and releases hydrogen ion leading to increase in acidity.

The newly prepared resins $\mathrm{K}-\mathrm{I}$ and $\mathrm{K}-\mathrm{II}$ are liquids and are soluble in $n$-hexane and methanol.

\subsection{Spectral analyses of model cardanol-formaldehyde resins, $K-I$ and $K-I I$}

The ultraviolet spectrum of the cardanol is given in figure 1, and those of $\mathrm{K}-\mathrm{I}$ and $\mathrm{K}-\mathrm{II}$ resins in figure 2. The UV spectral data are given in table 3 . The spectra of the resins indicate a shift of peak towards the lower wavelength. The shift of the peak from 247 to 228 in the case of K-I resin and to 237 in the case of K-II resin is due to ortho substitution in cardanol. Such a shift was also observed in phenol with alkyl substitution in ortho position (Silverstein et al 1981).

IR spectral analyses of $\mathrm{K}-\mathrm{I}$ and $\mathrm{K}-\mathrm{II}$ resins are given in table 4. The IR spectrum 

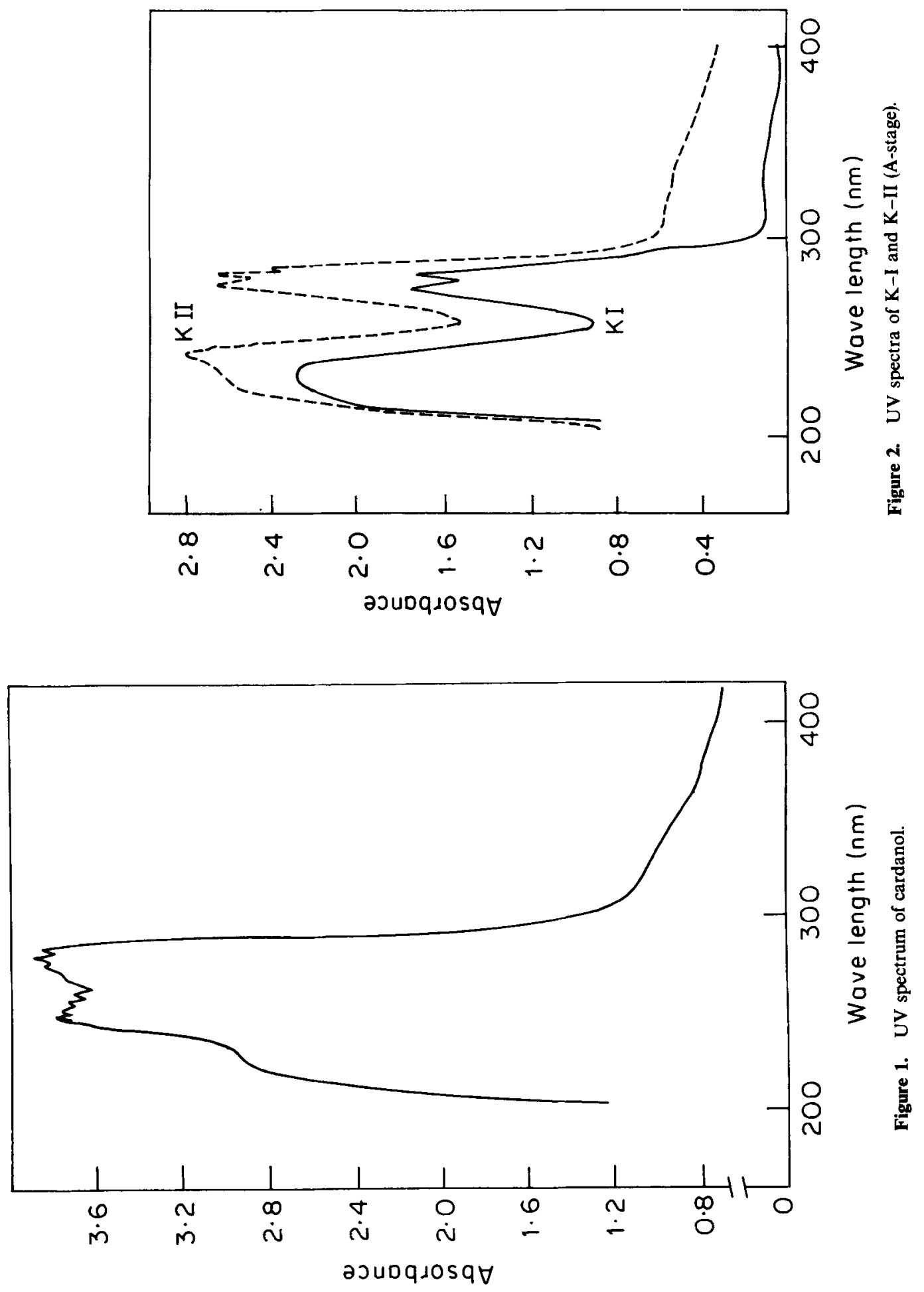
Table 3. UV spectral data of model cardanolformaldehyde resins.

\begin{tabular}{lccc}
\hline & \multicolumn{2}{c}{ UV absorption (wavelength in $\mathrm{nm}$ ) } \\
\cline { 2 - 4 } Responses & Cardanol & K-I & K-II \\
\hline Substitution & 247 & 228 & 237 \\
Aromatic & 278 & 272 & 272 \\
(doublet) & 282 & 280 & 280 \\
\hline
\end{tabular}

Table 4. IR spectral data of model cardanol formaldehyde resins.

\begin{tabular}{|c|c|c|c|}
\hline Peak $\mathrm{cm}^{-1}$ & Response & $\mathrm{K}-\mathrm{I}$ & $\mathrm{K}$-II \\
\hline $\begin{array}{l}3700-3100 \\
\text { broad peak } \\
\text { centering } 3370\end{array}$ & $\begin{array}{r}-\mathrm{CH}_{2} \mathrm{OH},-\mathrm{OH} \text { and } \\
\text { hydrogen bonding }\end{array}$ & $\mathbf{S}$ & $\mathrm{S}$ \\
\hline 3020 & $\begin{array}{l}\text {-CH stretching } \\
\text { aromatic-hydrogen } \\
\text { stretching }\end{array}$ & $\mathbf{S}$ & $\mathbf{S}$ \\
\hline $2915-2860$ & $\begin{array}{l}-\mathrm{CH} \text { stretching } \\
\text { from }-\mathrm{CH}_{2}\end{array}$ & $\mathrm{~S}$ & $\mathrm{~S}$ \\
\hline 1720 & $\begin{array}{l}\mathrm{C}-\mathrm{O} \text { stretching from } \\
\mathrm{CH}_{2} \mathrm{OH}\end{array}$ & W & $\mathbf{M}$ \\
\hline 1600 & $\begin{array}{l}\text { Unsaturation (un- } \\
\text { conjugated) }\end{array}$ & $\mathrm{S}$ & $\mathbf{S}$ \\
\hline 1450 & $\begin{array}{l}\text { Alcoholic -OH } \\
\text { deformation }\end{array}$ & $\mathrm{S}$ & $\mathrm{S}$ \\
\hline 1250 and 1150 & $\mathrm{C}-\mathrm{O}$ stretching & $\mathrm{S}$ & $\mathbf{M}$ \\
\hline 1100 & $\begin{array}{l}\mathrm{C}-\mathrm{O} \text { stretching } \\
\text { from } \mathrm{CH}_{2} \mathrm{OH}\end{array}$ & W & W \\
\hline 975,950 & $\begin{array}{l}\text { Substitution at } \\
\text { benzene nuclei }\end{array}$ & W & W \\
\hline 785,705 & $\begin{array}{l}3 \text { adjacent hydrogen } \\
\text { atoms in the benzene } \\
\text { nucleus }\end{array}$ & $\mathbf{M}$ & $\mathbf{M}$ \\
\hline
\end{tabular}

$\mathrm{S}=$ strong, $\mathrm{W}=$ weak, $\mathrm{M}=$ medium.

of cardanol is given in figure 3 and those of $\mathrm{K}-\mathrm{I}$ and $\mathrm{K}-\mathrm{II}$ resins in figure 4. A shift of a weak peak from 1050 to $1100 \mathrm{~cm}^{-1}$ and appearance of peak at $1720 \mathrm{~cm}^{-1}$ were observed in methylolated cardanol due to the $\mathrm{CO}$ stretching from $\mathrm{CH}_{2} \mathrm{OH}$. The bands at 975 and 950 also indicate the substitution at cardanol. Substitution at ortho position is exhibited by the weak band at $725 \mathrm{~cm}^{-1}$ in $\mathrm{K}-\mathrm{I}$ and $\mathrm{K}-\mathrm{II}$ resins.

The NMR spectrum of cardanol is given in figure 5 and that of resins in figure 6 . The appearance of a peak at $2.8 \delta$ of $\mathrm{K}-\mathrm{I}$ and $\mathrm{K}-\mathrm{II}$ is due to the benzylic protons of the $\mathrm{CH}_{2} \mathrm{OH}$ group formed during methylolation. The peaks at 6.7 and $6.8 \delta$ are due to the aryl protons. The peaks around the region $6.4 \delta$ are for the phenolic 


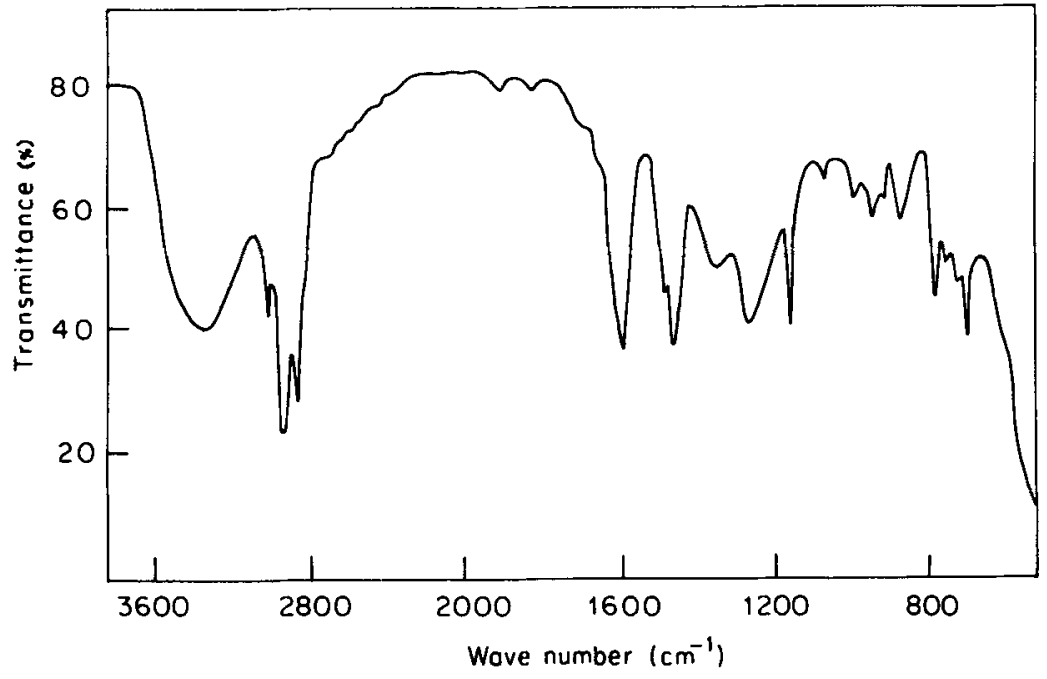

Figure 3. IR spectrum of cardanol.

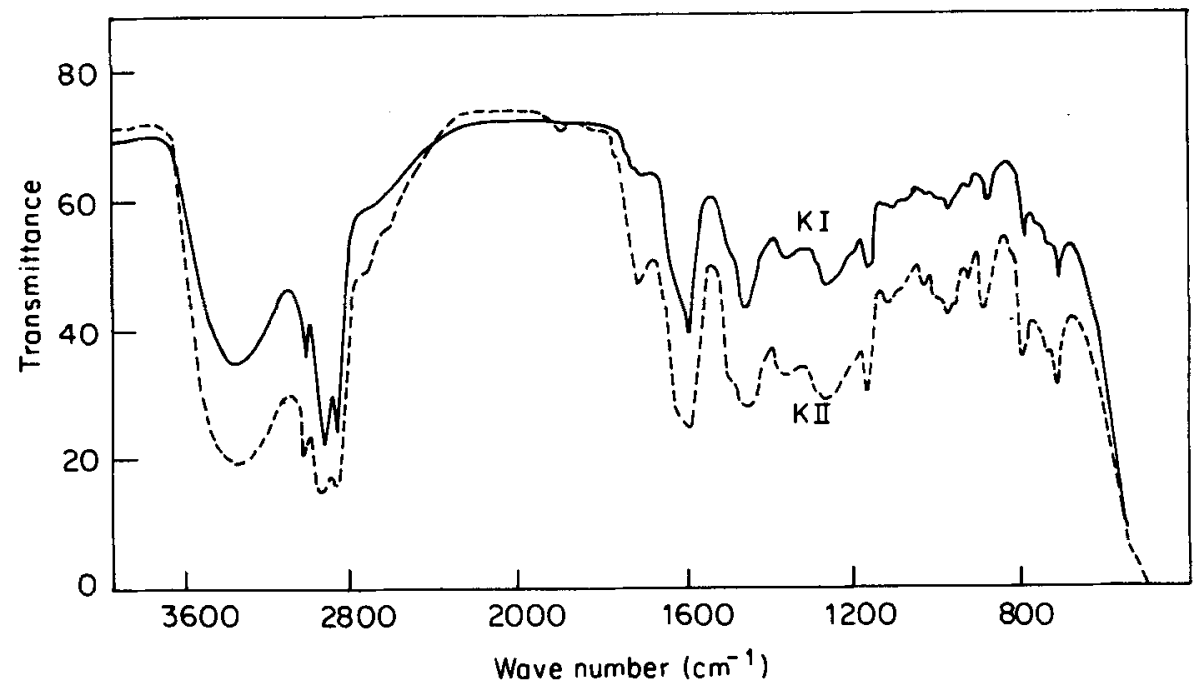

Figure 4. IR spectra of K-I and K-II (A-stage).

hydroxyl. The peak at $5 \cdot 1 \delta$ is due to the methylene proton of long alkyl side chain originally present in cardanol. The peaks between 0.8 and $2.4 \delta$ are due to the aliphatic long chain- $\mathrm{C}_{15} \mathrm{H}_{27}$ group of the cardanol. The small peak at $0.8 \delta$ represents the terminal methyl group of the chain. The strong peak at $1.3 \delta$ is attributed to the long chain ( $>5$ member) of the side chain.

Spectral studies indicate that the initial formylation of cardanol leads to methylola- 


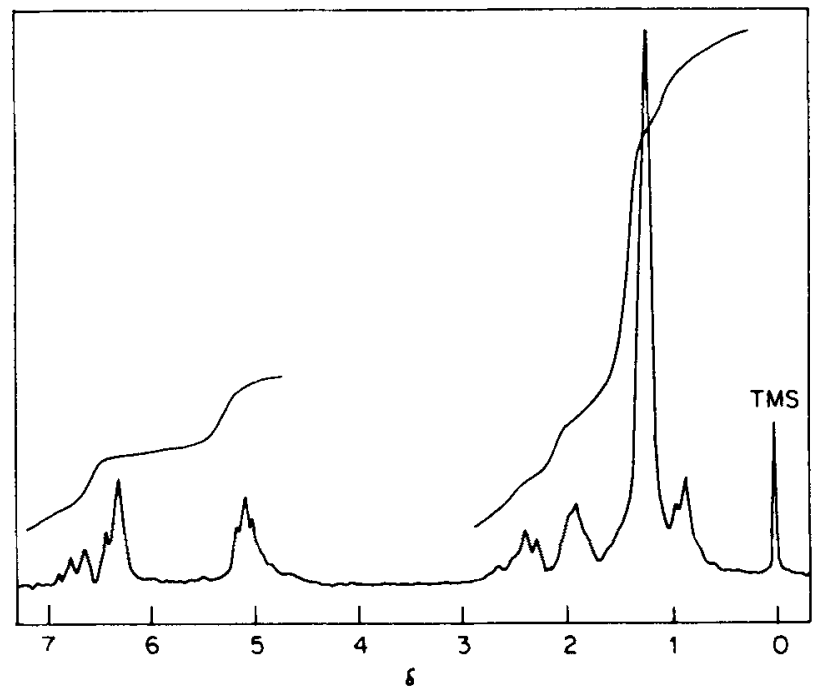

Figure 5. $\mathrm{H}^{\prime} \mathrm{NMR}$ spectrum of cardanol $(60 \mathrm{M} \mathrm{Hz})$.

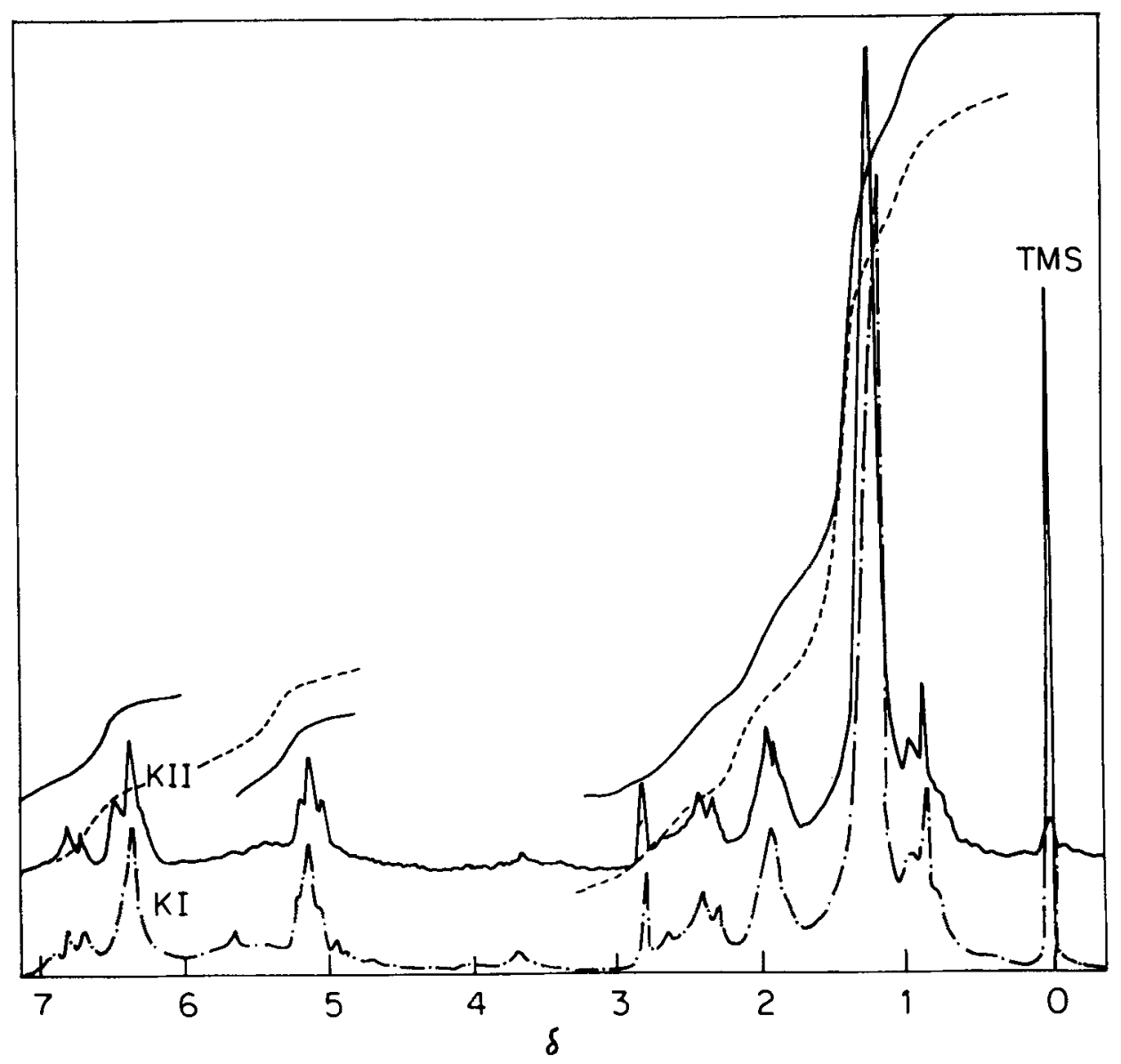

Figure 6. $\mathrm{H}^{\prime}$ NMR spectrum of $\mathrm{K}-\mathrm{I}$ and $\mathrm{K}-\mathrm{II}$ (A-stage) $(60 \mathrm{MHz})$. 


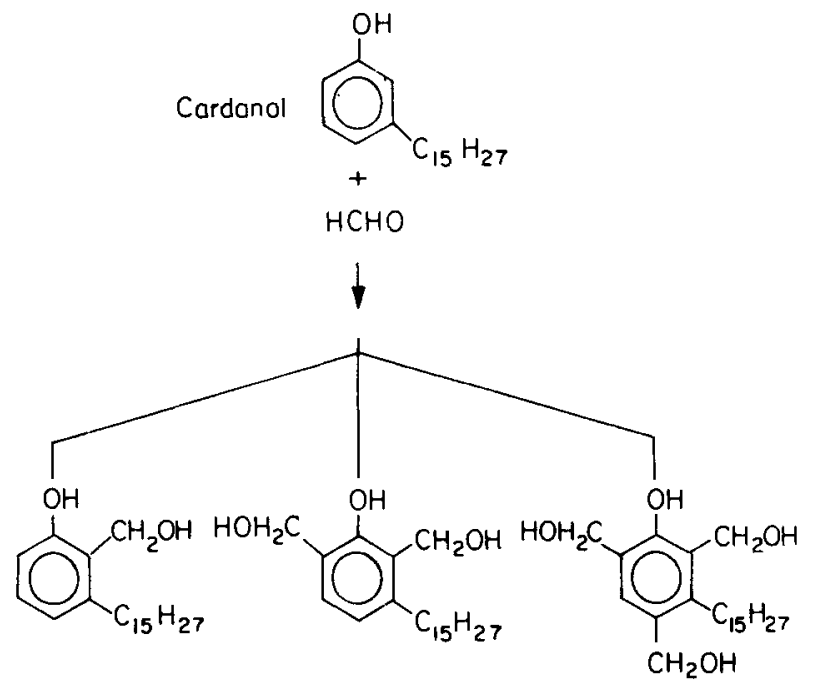

Methylolated cordanols

Scheme 1.

tion under the present experimental conditions ranging from single to triple substitution as shown in scheme 1 .

\subsection{Kinetics of curing reaction of model cardanol-formaldehyde resins, $K-I$ and $K-I I$}

The kinetics of the curing reaction of the present methylolated cardanol are different from the initial reaction of cardanol with formaldehyde. This is not only due to the influence of metta-substituted long chain but also because the $\mathrm{pH}$ of the methylolated cardanol is reduced from 4 to 2 . Therefore, further reaction occurs as an acid-catalysed novolac condensation. The differential thermal analysis scans of the curing reactions are given in figure 7 . The methylolated phenol condenses rapidly with phenol or phenol-ended polymer molecules, in the presence of an acid catalyst (Kakiuchi and Otsu 1952). This condensation rate is five to eight times as fast as the initial addition reaction (Kakiuchi and Otsu 1952). According to Little (1962) the overall reaction rate is a function of the acidity; the lower the $\mathrm{pH}$, the faster the reaction. A different trend has been observed with metta-substituted phenol where substitution increases reactivity at ortho and para positions. Therefore the initial formylation of mettasubstituted phenol is quite fast. However the subsequent curing rate is slower than that of the unsubstituted phenol (Redfarn 1942).

The present curing reaction is depicted by the appearance of exothermic peak in DTA scan when assessed (figure 7). The curing temperatures of K-I and K-II resins are given in table 5 where both the resins exhibit two exothermic peaks. The first peak for $\mathrm{K}$-II appeared at $74^{\circ} \mathrm{C}$ indicating low temperature reactivity. $\mathrm{K}$-II was prepared with mole ratio 0.8 and therefore the availability of formaldehyde for the initial methylolation reaction is greater in comparison to $\mathrm{K}-\mathrm{I}$ prepared with the mole ratio 0.6 . The higher mole ratio leads to varied degrees of methylolation ranging from single substitution in ortho position to triple substitution in both ortho and para positions; the fraction of single substituted cardanol may be the lowest. The 


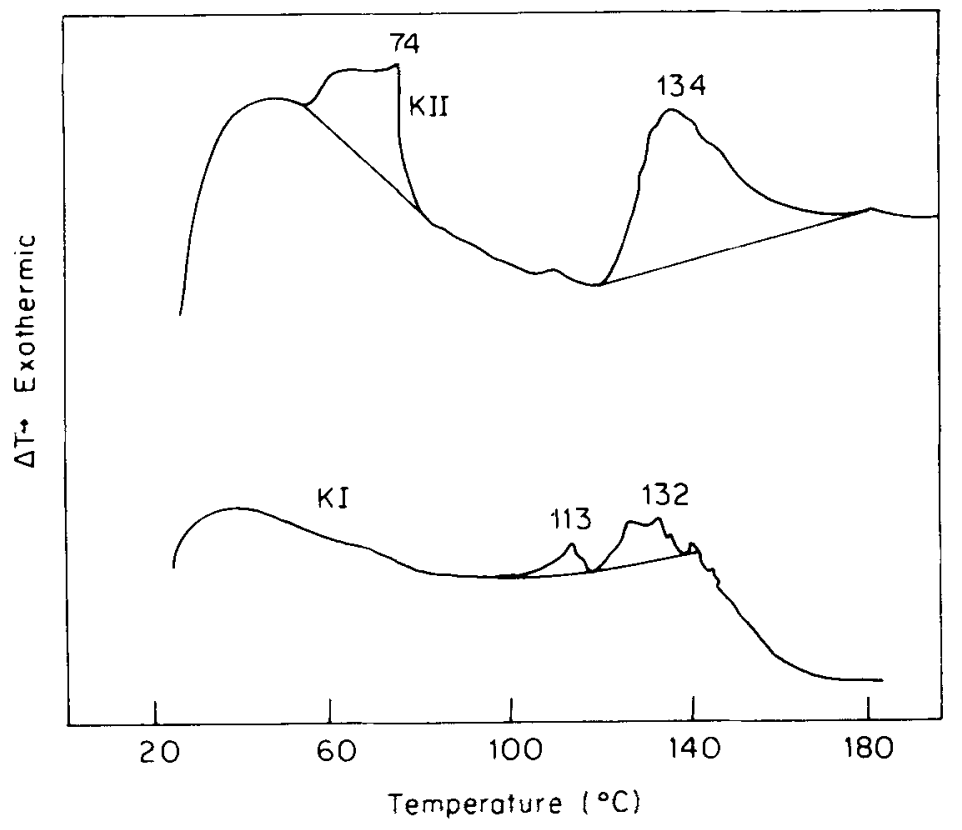

Figure 7. Curing reaction thermograms of K-I and K-II (DTA).

Table 5. Data on curing reactions (kinetics) of model cardanol formaldehyde resins.

\begin{tabular}{|c|c|c|c|c|c|c|c|c|}
\hline \multirow[b]{3}{*}{ Resin } & \multicolumn{4}{|c|}{ First exotherm } & \multicolumn{4}{|c|}{ Second exotherm } \\
\hline & \multicolumn{3}{|c|}{$\begin{array}{l}\text { I curing temperature } \\
\qquad\left({ }^{\circ} \mathrm{C}\right)\end{array}$} & \multirow{2}{*}{$\begin{array}{l}\text { I curing } \\
\text { time } \\
\text { (min) }\end{array}$} & \multicolumn{3}{|c|}{$\begin{array}{l}\text { II curing temperature } \\
\qquad\left({ }^{\circ} \mathrm{C}\right)\end{array}$} & \multirow{2}{*}{$\begin{array}{c}\text { II curing } \\
\text { time } \\
\text { (min) }\end{array}$} \\
\hline & Initial & Peak & Terminal & & Initial & Peak & Terminal & \\
\hline $\mathrm{K}-\mathrm{I}$ & 101 & 113 & 117 & $9 \cdot 0$ & 117 & 132 & 137 & 11.0 \\
\hline $\mathbf{K}-$ II & 54 & 74 & 77 & $5 \cdot 0$ & 118 & 134 & 168 & 11.0 \\
\hline
\end{tabular}

methylolated cardanol having substitution only at ortho position leads to faster condensation at lower temperature to complete the methylolation in other positions of cardanol. The curing time associated with the first exothermic peak for $\mathrm{K}-\mathrm{II}$ is lesser than that of $\mathrm{K}-\mathrm{I}$ (table 5). The second exothermic peak for $\mathrm{K}-\mathrm{I}$ and $\mathrm{K}-\mathrm{II}$ resins is attributed to the condensation of methylolated (ortho, ortho and parasubstituted) cardanol to give a linear structure.

During the initial curing of methylolated phenol with hexamine, three reactions are possible (Sprung and Gladstone 1949; Hoyt et al 1958): (i) Formation of ether linkage between two phenol rings, (ii) formation of methylene linkage between two phenol rings and (iii) formation of quinonoid structure.

The linear structures expected to form with the present methylolated cardanol are shown in scheme 2 . From the kinetics of curing reaction it is inferred that $\mathrm{K}-\mathrm{II}$ is initially fast reactive in comparison to $\mathrm{K}-\mathrm{I}$. 

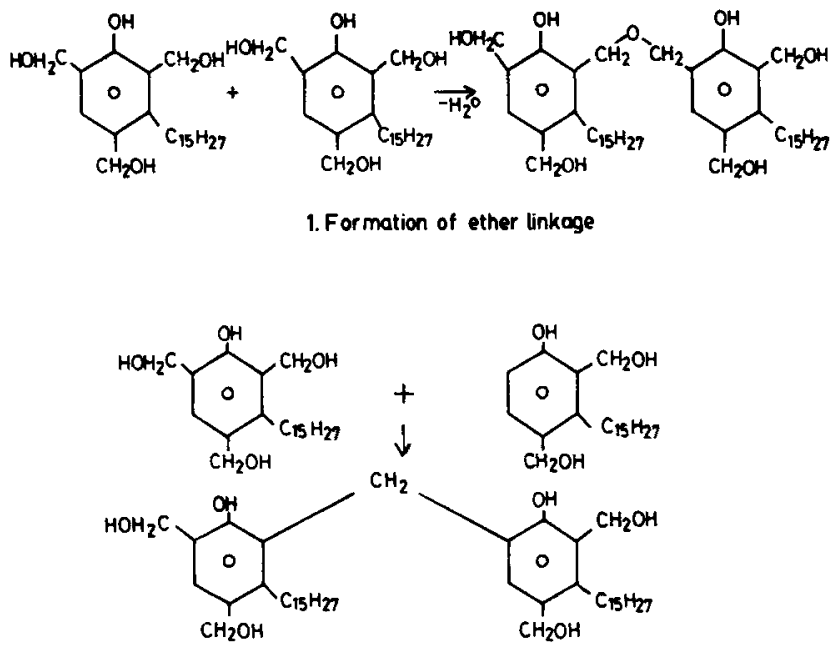

2. Formation of methylene linkage

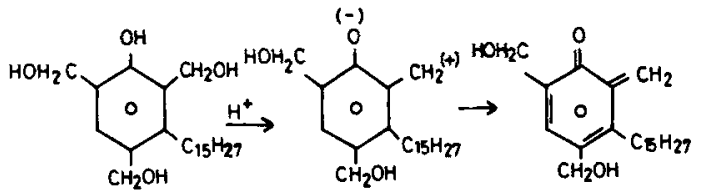

3. Formation of quinonoid structure

Scheme 2.

\subsection{Curing and characterization of model cardanol-formaldehyde resin}

The characterization of cured resin was aimed at finding out the structure of the linear polymer formed during preliminary curing. The IR spectra of the cured B-stage resins are given in figure 8 . The intensity of the bands for the $-\mathrm{CH}_{2} \mathrm{OH}\left(3332 \mathrm{~cm}^{-1}\right)$, alcoholic $-\mathrm{OH}$ of $\mathrm{CH}_{2} \mathrm{OH}\left(1450 \mathrm{~cm}^{-1}\right)$, and $-\mathrm{OH}\left(1250\right.$ and $\left.1150 \mathrm{~cm}^{-1}\right)$, reduced appreciably in $\mathrm{K}-\mathrm{I}$ resin. Interestingly in $\mathrm{K}$-II cured resin small peaks appeared at $950-975$ and $1225 \mathrm{~cm}^{-1}$ intensity. There was a new band at $825 \mathrm{~cm}^{-1}$. The weak band at $725 \mathrm{~cm}^{-1}$ became more clear and distinct. These bands are attributed to the increased substitution at ortho and para positions. The band at $725 \mathrm{~cm}^{-1}$ indicates the presence of ortho-ortho linkage in this partially cured resin. Phenolic novolac resins showed absorbance at $760 \mathrm{~cm}^{-1}$ for ortho-ortho and $825-840 \mathrm{~cm}^{-1}$ for ortho-para linkages. The intensity of the former was higher for high ortho novolac (Fraser et al 1957). Cardanol novolac showed these absorbances in lower level due to substitution in metta position.

\subsection{Development and testing of glass fabric laminates}

IR spectral studies on the model cardanol-formaldehyde B-stage resin indicate that methylolated cardanol condenses with formaldehyde in ortho-ortho and ortho-para positions with higher degree of ortho-ortho linkage. Such resins are expected to give 


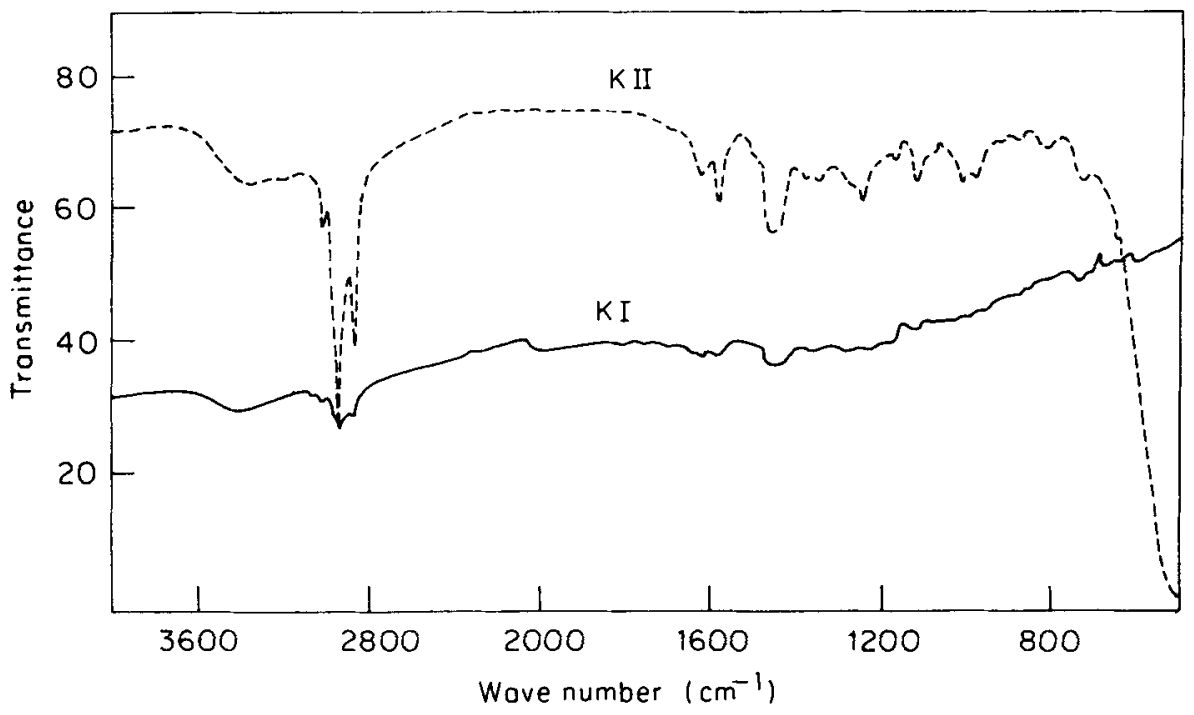

Figure 8. IR spectra of cured $\mathrm{K}-\mathrm{I}$ and $\mathrm{K}$-II resin (B-stage, $18 \%$ hexamine).

Table 6. Water absorption of CNSL Novolac laminate.

\begin{tabular}{llc}
\hline $\begin{array}{l}\text { Period of } \\
\text { immersion } \\
\text { (days) }\end{array}$ & \multicolumn{2}{c}{ Weight gain } \\
\cline { 2 - 3 } & \multicolumn{1}{c}{ gm } & $\%$ \\
\hline 7 & $0.030 \pm 0.002$ & $3.3 \pm 0.2$ \\
14 & $0.072 \pm 0.010$ & $7.98 \pm 1.1$ \\
21 & $0.075 \pm 0.010$ & $8.31 \pm 1.1$ \\
28 & $0.076 \pm 0.012$ & $8.42 \pm 1.3$ \\
35 & $0.076 \pm 0.01$ & $8.42 \pm 1.1$
\end{tabular}

Weight of the sample, $0.9026 \mathrm{~g}$; Number of specimen, 6.

curing speed higher than that of resins with high para linkage (Bender et al 1949). $\mathrm{K}$-II resin was found to possess superior curing characteristics compared to $\mathrm{K}-\mathrm{I}$ with hexamine. Hexamine has been generally used for curing of phenolic resins to get a thermoset. Hexamine sublimes quite rapidly at $150^{\circ} \mathrm{C}$. The three bonds associated with one of the nitrogen atoms of hexamine molecule opens to react at the end group of phenol ring of three separate novolac chains. CNSL novolac resin prepared using $\mathrm{K}$-II formulation was used to prepare glass fabric laminate. The tensile properties of the laminate were $14.65 \pm 2.85 \mathrm{KN} / \mathrm{cm}^{2}$ (tensile strength) and $3.8 \pm 0.8(\%$ elongation).

The tensile strength of the candidate laminate is comparatively higher than that of laminate prepared with high ortho novolac reported earlier. Jayabalan and Rajadurai (1985) reported a tensile strength of $12.60 \pm 2.5 \mathrm{KN} / \mathrm{cm}^{2}$ for their laminate prepared with resin synthesized from CNSL, formalin and $m$-cresol (accelerator) at $\mathrm{pH} 8.0$ with mole ratio $0 \cdot 8$. The presence of long chain with unsaturated double bonds can lead to a certain degree of internal plasticization in the cured thermoset. Such characteristics can give comparatively low tensile strength but can also give high impact resistance 
compared to that of phenolic resin. The data of water absorption of the candidate laminate are given in table 6 . Water absorption attained an equilibrium after the post-immersion period of 14 days with absorption around $8 \%$. The laminate did not attain delamination even after the post-immersion period of 35 days, thereby indicating that the laminate possesses good interlaminar adhesion.

\section{Conclusion}

Succinic acid catalyses the formylation of cardanol. Subsequent curing leads to high ortho novolac resin.

The model cardanol formaldehyde resin prepared with mole ratio of 0.8 possesses good curing characteristics. The initial curing rate of this resin is not only influenced by the presence of long chain in the cardanol and $\mathrm{pH}$ of the curing reaction but also by the level of fraction of singly-substituted formylated cardanol. CNSL resin prepared with this formulation and the resultant laminate have good mechanical properties and dimensional stability. These laminates can be used as secondary load-bearing structures or panels.

\section{References}

Bender H L, Farnham A G and Guyer J W 1949 March 15 US Pat. 2, 464, 207

Dhler J G 1979 Cashew (Amsterdam: Royal Tropical Institute) ed. 1, p. 21

Finn S R and Murty J W G 1950 J. Soc. Chem. Ind. (London) 69549

Fraser D A, Hall R W and Reun J L 1957 J. Appl. Chem. (London) 7676

Freeman J H and Traylar E J 1961 J. Soc. Plastics Eng. 17673

Hoyt H E, Keuchel H W and Dean R B 1958 Paint and Varnish Prod. 4833

Jayabalan M and Rajadurai S 1985 Popular Plastics 3030

Kakiuchi H and Otsu T 1952 Chem. High Polym. Japan 9303

Little G E 1962 J. Appl. Chem. (London) 12196

Murthy B G K, Sivasamban M A and Aggarwall J S 1968 J. Chromatogr. 32519

Redfern C A 1942 Br. Plast. 13481

Silverstein R M, Clayton G and Morrill T C 1981 Spectrometric identification of organic compounds (New York: John Wiley) ed. 4, pp. 305

Sperling G R $1954 \mathrm{~J}$. Am. Chem. Soc. 761190

Sprung M M and Gladstone M T $1949 \mathrm{~J}$. Am. Chem. Soc. 712907

Tyman J H P 1979 Chem. Soc. Rev. 8499

Urbanski J, Czerwinski W, Ianika K, Majewsta F and Zowall H 1977 Handbook of analysis of synthetic polymers and plastics, (Chichester: Ellis Horwood) p. 179 